\title{
Çocuk hastada nadir görülen katater komplikasyonu: Olgu sunumu
}

\author{
Sibel Oba ${ }^{1}$, Meltem Aydoğmuş ${ }^{1}$, Özgür Özbağrıaçık', Mehmet Eren Açık², Saliha Berber Pehlivan²
}

\begin{abstract}
ÖZET:
Çocuk hastada nadir görülen katater komplikasyonu: Olgu sunumu Implante damar erişim cihazları pek çok hematolojik ve onkolojik hastalığın tedavisinde kullanılmaktadır. İntravenöz tedavinin zorluğunu belirgin olarak azaltır ve onkoloji hastalarının yaşam kalitesini arttırırlar. Deneyimli ellerde komplikasyon oranı çok düşüktür. Bununla birlikte kullanıcıların eğitilmesi, katater bakımının sık ve uygun şekilde yapılması, takıldıkdan sonra uygun şekilde kullanılması gereklidir. Biz bu olguda uygunsuz kullanım sonrası delinme ve sızıntı gelişen port katateri komplikasyonunu sunmayı amaçladık.

Anahtar kelimeler: Venöz port komplikasyonu, santral venöz kateter

\section{ABSTRACT:}

A rare complication of totally implantable venous access device in a pediatric patient: a case report

Implanted vascular access devices (ports catater) are widely used in pediatric haematology and oncology patients. They reduce the intravenous therapy difficulties and increase the quality of lives of oncologic patients. Complications are rare with experienced hands. Education of users, correct and frequent care, appropriate postoperatively use are important. Correct procedure and careful usage decrease the incidence of complications. We present a case where a perforation and leakage of ports catater occured due to improper usage.

Key words: Venous port complication, central venous catheter
\end{abstract}

Ş.E.E.A.H. Tıp Bülteni 2013;47(1):41-44
${ }^{1}$ Uzm. Dr., ${ }^{2}$ As. Dr., Şişli Etfal Eğitim ve Araştırma Hastanesi, Anesteziyoloji ve Reanimasyon Kliniği, İstanbul-Türkiye

Yazışma Adresi / Address reprint requests to: Şişli Etfal Eğitim ve Araştırma Hastanesi, Anestezi ve Reanimasyon Kliniği, Şişli, İstanbul-Türkiye

Telefon / Phone: +90-212-373-5000/5477

E-posta / E-mail:

sibel.oba@sislietfal.gov.tr

Geliş tarihi / Date of receipt: 28 Haziran 2012 / June 28, 2012

Kabul tarihi / Date of acceptance: 21 Eylül 2012 / September 21, 2012

\section{GíRiş}

Santral venöz port sistemleri modern onkolojide ve hematolojik hastalıklarda, kısa süreli ya da kalıcı tünelli santral venöz kateterlerin yerini almakta, devamlı venöz erişim sağlamada hayati rol oynamaktadırlar $(1,2,3)$. Tekrarlanan kemoterapi, parenteral beslenme, transfüzyon, infüzyon, enjeksiyon ve kan örneği alınması gibi uzun dönem intravenöz tedavi uygulanması gereken hastalara yerleştirilmektedir $(2,4)$. Bu kateterler, cilt altında tünelize edilirler ancak postoperatif uygun şekilde kullanılması gerekmektedir (1). Biz bu olguda uygunsuz kullanım sonrası delinme ve sızıntı gelişen port katateri komplikasyonu olgusunu sunmayı amaçladık.

\section{OLGU}

6600 gram, 7 aylık kız bebek, çocuk hastalıkları kliniğinde port katateri takılması istemi nedeni ile değerlendirildi. Öyküsünden 3.5 aylık iken solukluk ve erken fontanel kapanması nedeni ile çocuk hastaIıkları kliniğine başvurduğu, hipokalsemi ve hepatosplenomegali saptanan hastaya hemofagositik sendrom tanısı konulduğu ve kemoterapi başlanmış olduğu bilgisi alındı. Yapılan tetkiklerinde beyaz küre 9600, hemoglobin 8.8, hemotokrit 26.3, trombosit 297000, potasyum 3.21, kalsiyum 8.41, magnezyum 1.72, GGT 89 idi. Diğer tetkikleri normal sınırlardaydı. Akciğer sesleri dinlemekle bilateral eşitti ancak bazallerde tek tük ral duyulmakta idi. Hastanın işlem öncesi akciğer grafisi Resim 1'de 


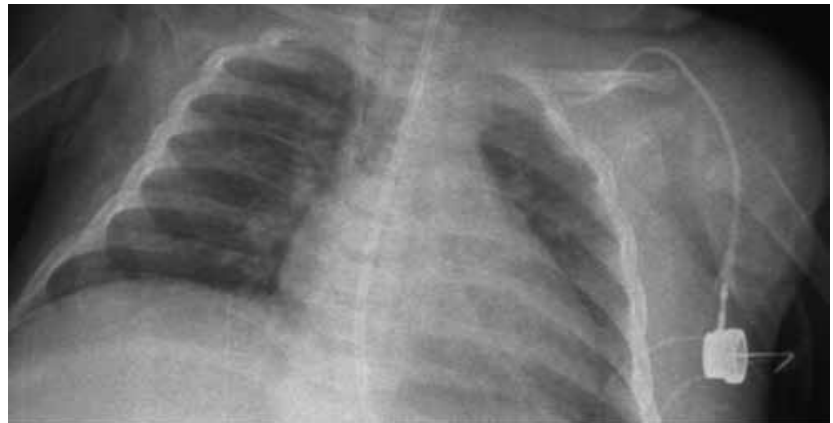

Resim 1: Hastanın işlem öncesi akciğer grafisi

görülmektedir. Amerikan Anestezi Derneği'nin skorlamasına göre ASA 1 olarak kabul edilen hastanın ailesinden bilgilendirilmiş olur alındı ve hasta işlem için hazırlandı. Kalp atım hızı, non invaziv kan basın$\mathrm{Cl}$ ve $\mathrm{SpO}_{2}$ monitorizasyonu yapıldı. İndüksiyon öncesi vital bulguları, $\mathrm{SpO}_{2} \%$ 97, kalp hızı 120 atım dk-1, non invaziv kan basıncı 90/60 mmHg idi. Hastaya intravenöz $10 \mu \mathrm{g}$ fentanil, $15 \mathrm{mg}$ propofol ve 5 mg rokuronyum ile anestezi indüksiyonu yapıldı. 4 numaralı kafsız tüp kullanılarak entübe edildi. Anestezi idamesine $\% 2$ sevofluran, $\% 50 \mathrm{O}_{2}$ ve $\% 50$ medikal hava ile devam edildi. Steril cerrahi koşullar sağlandıktan sonra, sağ subklavyen venden perkütan yolla girildi. Ancak katater yerleştirilemedi. Bu nedenle sol subklavyen venden perkütan yolla $4.5 \mathrm{~F}$ port katater takıldı. İşlem sonrası floroskopi ile kata-

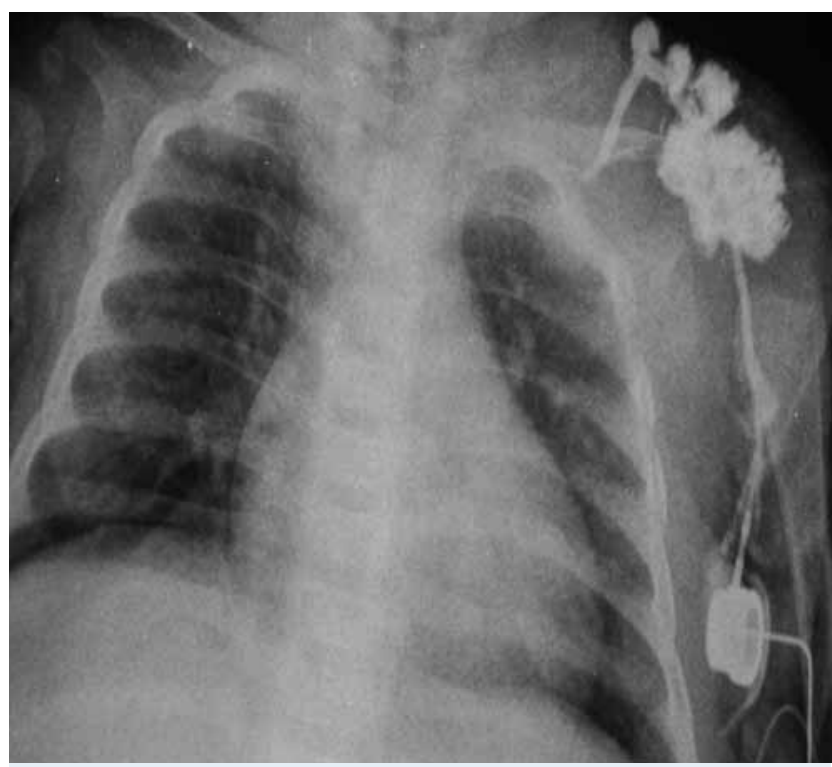

Resim 2: Kontrast madde verildikten sonra çekilen akciğer grafisi terin yeri doğrulandı ve kataterin çalıştığı tespit edildi. İntravenöz $0.1 \mathrm{mgr}$ atropin ve $0.2 \mathrm{mgr}$ neostigmin verilerek dekürarize edildikten sonra, sorunsuz bir şekilde ekstübe edildi ve çocuk hastalıkları kliniğine gönderildi. İşlemden 1 gün sonra port kataterin takıldığı yerden sıvı sızdığı bilgisi alındı. Hasta tekrar değerlendirildi. Kontrast madde verilerek çekilen akciğer grafisinde verilen kontrastın kataterden dışarı dağıldığı gözlemlendi (Resim 2). Bunun üzerine port katater çekildi. Yapılan incelemede katater üzerinde multiple delikler olduğu saptandı.

\section{TARTIŞMA}

Santral venöz port sistemleri modern onkoloji ve hematolojik hastalıklarda, kısa süreli ya da kalıcı tünelli santral venöz kataterlerin yerini almakta, devamlı venöz erişim sağlamada hayati rol oynamaktadırlar (1-3). Tekrarlanan kemoterapi, parenteral beslenme, transfüzyon, infüzyon, enjeksiyon ve kan örneği alınması gibi uzun dönem intravenöz tedavi uygulanması gereken hastalara yerleştirilmektedir (2-4). Bu kataterler, cilt altında tünelize edilirler ancak katater bakımının sık ve uygun yapılması, postoperatif uygun şekilde kullanılması gerekmektedir (1). Port sisteminin yerleştirilmesi detaylı bir planlama, hazırlık ve dikkatli bir uygulama gerektirir (2). Port kataterin yerleştirilmesi sırasında, kataterin ucu vena cavaya ulaşmalıdır. Kateterin ucu ancak bu pozisyonda ise büyük bir kan volumu geçer ve verilen medikasyon hızlıca dilüe olarak damar duvarına zarar vermez. Pek çok kemoterapi ilacı yüksek ozmolariteli solüsyonlar olarak hazırlanmaktadır (2). Bu ilaçlar periferik ven duvarına sklerozan etki ile hasar verebilir ve periferal erişimi sonlandırabilir $(2,5)$. Daha önceden kemoterapi, radyoterapi ve/veya cerrahi geçirmiş hastalarda anatomik yapı normalden farklı olabilir. Cilt, yumuşak doku, ven veya omuz eklemine ait kemiklerde majör değişiklikler olabilir. Venöz tromboz ve anatomik farklılıkları tespit etmek için işlem öncesi santral venlere ultrasonografi (USG) yapılması önerilmektedir (2).

Port sistemleri subklavyen ven, sefalik venler, basilik ven ve internal juguler vene yerleştirilebilir. Çocuklarda eksternal jugule ven de kullanılabilir. Nadir vakalarda, çeşitli nedenlerle diğer venlere 
uygulanamamışsa, büyük safen ven de kullanılabilir (2). Zhang ve arkadaşları çocuklarda eksternal juguler vene cut down ile port yerleştirilmesinin, subklavyen ven ponksiyonundan belirgin olarak daha iyi olduğunu önermişlerdir (3).

Port sistemi takılması sırasında gelişebilecek komplikasyonlar 3'e ayrılır (1-2):

\section{Cerrahi komplikasyonlar:}

1. İstenmeyen arteriyel ponksiyon

2. hava embolisi

3. pnömotoraks

4. hematom

5. perforasyon (kalp, majör damar yaralanması)

6. kardiyak aritmiler

7. pleksus irritasyonu.

\section{Kateter bağımlı komplikasyonlar:}

1. Kateter dislokasyonu

2. kateter sıkışması ( pinch-off sendromu)

3. kateterden sızıntı ya da embolizm

4. fibrinöz şit

5. kateter tromboz ya da tıkanması

6. port rezervuarının torsiyon ya da migrasyonu

7. enfeksiyon

8. cilt nekrozu

9. malpozisyon.

\section{Vasküler komplikasyonlar:}

1. Tromboz

2. Arteriovenöz fistül.

Deneyimli ellerde komplikasyonlar $\% 2$ 'den daha az olmakla birlikte, komplikasyon oranı \%4.3-46 arasında bildirilmiştir. Erken komplikasyonlar implantasyondan sonra 24 saat- 4 hafta arasında, geç komplikasyonlar 4 haftadan sonra gelişir. Geç komplikasyon- lar port implantasyon prosedürü ile alakalı değildir (2).

Port sistemi kullanımı sırasında enfeksiyon oranı son klinik çalışmalarda \%0,8 ile \%7,5 arasında bildirilmiştir (2). Yapılan bir çalışmada port katateri ile birlikte vena kava trombozuna bağlı superior vena kava sendromu geliştiği bildirilmiştir (6). İşlem sonrası doktor ve hemşireler port kullanımı için eğitilmelidir. Eğer port sistemi yıkanamıyorsa ve aspire edildiğinde kan gelmiyorsa sistemde bir tıkanıklık olabileceği göz önünde tutulmalıdır. Tıkanıklık genellikle kan pıhtısı, parenteral nutrisyon kalıntısı ve ilaçlardan kaynaklanır. Port sistemi yıkayarak açılamıyorsa radyografik kontrast verilerek kontrol edilmelidir. Kontrast port iğnesi ile enjekte edilir ve floroskopi çekilir. Kateterin hareketi katlanmasına veya kateter ucunun yanlış yerleşimine neden olabilir. Ayrıca fonksiyonel bir portun başta iyi çalışırken kullanımda zorluk oluşması, kateterin ucuna yakın çevrede fibrin oluşumuna da bağlı olabilir (2).

Sistem her kullanımdan önce 20 mL \%0.9 salinle yıkanırsa, bir problem olması durumunda hastada basınç ve yanma hissiyle gelişecektir. $10 \mathrm{~mL}$ 'nin altındaki enjeksiyonlar porttan verilmemelidir. Çünkü daha yüksek basınçla enjeksiyon yapılması gerekecek, bu durumda kateterde ayrılma ve yırtılmaya neden olabilecektir. Bu durumda hasarlı sistem çıkarılmalıdır (2). Ekstravazasyon, bağlantı bölgelerinin gevşemesi ya da dislokasyona bağlı olarak da görülebilir (1).

Bizim olgumuzda kontrast verdikten sonra çekilen akciğer grafisinden, sızıntının portun katater kısmında bir delinmeye bağlı olarak gelişebileceğini düşündük. Bunun uygunsuz kullanım tekniği nedeni ile, aşırı basınç uygulanarak zorlamaya ya da uzun bir iğne kullanımına bağlı olabileceğini düşündük. Port çıkartıldıktan sonra yaptığımız incelemede, bağlantı bölgelerinin sağlam olduğunu, ancak katater üzerinde multiple delikler olduğunu gördük.

Sonuç olarak, port katateri takıldıktan sonra kullanıcıların eğitilmesinin, oluşabilecek komplikasyonları önemli ölçüde azaltabileceğini düşünmekteyiz.

\section{KAYNAKLAR}

1. Babu R, Spicer RD. Implanted vascular access devices (ports) in children: complications and their prevention. Pediatr Surg Int 2002;18:50-53.

2. Teichgräber UK, Pfitzmann R, Hofmann HA. Central venous port systems as an integral part of chemotherapy. Dtsch Arztebl Int 2011;108(9):147-53. 
3. Zhang Q, Jiao L, Zhou H. Comparison of implantable central venous ports with catheter insertion via external jugular cut down and subclavian puncture in children: single center experience. Pediatr Surg Int 2009; 25(6):499-501.

4. Güleser GN, Taşçı S. Onkolojide Sık Kullanılan Santral Venöz Kateterleri ve Bakımı. F Ü Sağ Bil Tıp Derg 2009;23(1):47-51.
5. Wu JR, Hsu JH, et al. Nonsurgical percutaneous retrieval of dislodged Port-A catheters from pulmonary artery in children. Jpn Heart J 2002; 43(3):295-300.

6. Dağdelen S. Arch Turk Soc Cardiol 2009;37(2):125-127. 